\title{
Interaction between Economic and Financial Development
}

\author{
Luca G. Deidda* \\ University of Sassari, CRENoS, and CeFiMS, SOAS (Un. London) \\ ld1@soas.ac.uk
}

November 1999

\begin{abstract}
This paper presents a possible explanation of the interactive nature of the relationship between economic and financial development based on absorption of resources by the financial sector, and constant returns to physical capital accumulation in the production sector. Financial intermediaries operating in a credit market characterised by monopolistic competition emerge along with the process of economic development. This could initially have a detrimental effect on growth, so that the economy might be trapped in a low development region. If not, subsequent economic development stimulates competition among financial intermediaries which results in more efficient financial transactions, and therefore higher growth. While higher efficiency is always associated with higher growth, the laissez faire economy can be still characterised by sub-optimal levels of financial development.
\end{abstract}

*I am highly indebted to Laurence Harris for his suggestions and encouragement. I also wish to thank Marco Pagano, Pasquale Scaramozzino, Philip Arestis, Carlo Casarosa, and seminar participants at University of Pisa, SOAS (Un. London), CEFS (Salerno), and SED99 (Alghero). All errors are of course mine. 


\section{Introduction}

In the $90 \mathrm{~s}$ a substantial amount of literature about the theoretical analysis of the link between economic and financial development has grown out of the new developments both in growth theory and financial institutions theory. ${ }^{1}$ Two sets of considerations have been emphasised:

$i$. Financial institutions provide insurance against productivity and illiquidity risks, and collect information to evaluate investment projects. These functions could improve the allocation of funds toward risky, and illiquid high return technologies;

ii. Costs associated with the technology for financial transactions are characterised by non-convexities. This implies economies to scale, so that financial institutions can endogenously emerge at some critical level of economic development.

Some of the existing models take the extent of financial intermediation, as well as the technology involved in financial transactions, as exogenous. In this type of models, real effects of financial institutions are analysed comparing the extreme situation in which there is complete absence of financial transactions, i.e. financial autarky, with the other extreme case in which all savings are channelled through investment by means of some exogenous financial technology. There are however some models which endogenise the extent of financial intermediation, like for example, Greenwood Jovanovic (1990), and Acemoglu-Zilibotti (1997). Based on the crucial assumption of heterogeneity of savers with respect to endowments, Greenwood and Jovanovic's model is characterised by a continuous relationship between economic and financial development, which stems from the fact the extent of participation of savers to a financial coalition (which operates as an intermediary) changes according to the level of economic development. ${ }^{2}$ In Acemoglu and Zilibotti, the portion of savings channelled toward growth inducing projects changes according to the level of economic development which positively reflects in the potential for risk diversification generated within the economy. These models shed light on potential reasons why real effects, and in particular growth effects, induced by financial institutions might be different at different stages of economic

\footnotetext{
${ }^{1}$ Pagano (1993) provides an excellent survey of seminal papers.

${ }^{2}$ However, this result is crucially dependent on the assumption that savers are heterogeneous with respect to their endowments.
} 
development. The intuition is that the performance of the financial sector is, in some way, related to the conditions of the real sector of the economy. ${ }^{3}$

In this paper we analyse the role of absorption of resources by financial institutions as another source of endogeneity of the real effects induced by the financial sector with respect to economic development. Taking into account resources consumption associated with the financial sector together with the existence of non-convexities associated with financial technologies provides a natural explanation for the existence of a continuous relationship between finance and growth, as the following very basic example based on Pagano (1993) shows. Assume a closed economy, with an $A K$ production function, such that gross investment is $I_{t}=K_{t+1}$. Let the saving rate under financial autarky be $s^{F A}$ and the saving rate under financial intermediation be $s^{F I}$. Assume that financial transactions imply consumption of resources equal to $E_{t}$. Then, the growth rate under financial autarky would be $s^{F A} A-1$, while if a financial sector is present the growth rate would be $s^{F I} A-1-\frac{E_{t}}{K_{t}}$. Two considerations emerge:

i. when a financial sector operates the growth rate is not necessarily constant, but it changes according to $K_{t}$ and $E_{t}$;

ii. in principle, financial development might have an ambiguous growth effect,no matter if $s^{F I}>s^{F A}$.

We introduce consumption of real resources by the financial sector in a simple OLG economy populated by risk-averse agents and competitive risk neutral firms. Agents are endowed with a safe but relatively unproductive technology, while firms have access to a more productive but risky one. Agents can either self-finance safe production or engage in financial transactions to fund firms. In first case they experience no risk. In the second case risk can be diversified away completely building a fully diversified portfolio of financial assets. Financial transactions imply costs which are modelled as consumption of real physical resources. Given the existence of economies to scale savers find it convenient to delegate investment-financing to financial intermediaries. These intermediaries issue deposits and fund firms via loans. Deposits constitute a safe asset since intermediaries fund a continuum of investment projects whose returns are i.i.d variables.

\footnotetext{
${ }^{3}$ Saint-Paul (1993) is another example of a model in which financial intermediation arises endogenously at some level of economic development. However, in this particular model, the growth effect of financial development it is still exogenous to the process of economic development.
} 
We shape the structure of the credit market according to a spatial model of monopolistic competition. In this respect the model is related to Sussman (1993). In that paper, the author uses a spatial model of monopolistic competition to show how: "[...] how changes in capital stock affect the structure and conduct of financial markets..."; Sussman (1993, p. 31). Here, we move the analysis one step further investigating "...the effect back into the capital stock (i.e. capital dynamics) [...]"; [ibid., p.31], which Sussman left as "[...] future work [...]"; [ibid., p.31]. Similarly to Sussman, we assume the monitoring technology available to financial intermediaries shows increasing returns to specialization. ${ }^{4}$ Given these assumptions the structure of the credit market, which is measured by the number of banks potentially operating in the sector, depends on the level of economic development measured by the stock of accumulated capital per head. In case of positive growth, as the stock of accumulated capital increases, per capita income and savings rise, so that the market for deposits enlarges. This ensures profitability of the banking sector increases, which provides incentives for new banks to enter the credit market. Inter-bank competition generated in this way increases the efficiency of the intermediaries operating in the credit market. Via this basic mechanism financial intermediation could endogenously develop at some critical level of economic development. The emergence of the credit market might turn out to have a negative immediate impact on growth. To be more precise the economy might face a temporary reduction in the growth rate during the period of transition from financial autarky to financial intermediation. This leads to the possibility of the economy being trapped in a low development equilibrium, such that the economy either cannot complete the transition to financial intermediation or experiences negative growth after transition so that financial intermediation is not sustainable even if it would bring positive effects later on in the process of economic development. Whenever the growth rate of the economy stays positive after transition to financial intermediation, although, initial effects of financial development might be detrimental for growth, subsequent evolution of the credit market would finally bring positive effects, so that the growth rate will be increasing over time up to a limit steady state upper bound, so that financial development would result in higher growth compared to financial autarky as long as this upper bound is, as one should reasonably expect, higher than the growth rate under financial autarky.

\footnotetext{
${ }^{4}$ Empirical evidence in support of the existence of economies of specialisation in financial intermediation is provided by a number of authors. With reference to the US banking sector see Sussman-Zeira (1996).
} 
The paper is organized as follows. Section 2 describes the structure of the model. In Section 3 describes agents' behaviour. Section 4 describes the economy under financial autarky. Section 5 describes the economy under financial intermediation. In section 6 we describe the interactive relation between financial and economic development emerging from the model. Section 7 describes some implications related to growth empirics. Final comments conclude the paper.

\section{The model}

The economy is composed by a continuum of size $H$ of individuals and a continuum of size $H$ of firms. All firms, as well as individuals, are identical. The population of individuals has a standard OLG structure, with individuals living for two periods. Each individual is endowed with a unit of labour in his or her first period of life. Individuals derive utility from consumption over the two periods according to

$$
U_{t}^{i}=\frac{c_{1, t}^{\gamma}-1}{\gamma}+\frac{1}{1+\rho} \frac{c_{2, t}^{\gamma}-1}{\gamma}
$$

where $U_{t}^{i}$ is the total life-time utility for the individual. ${ }^{5}$ During their first period of life agents supply labour to producers. Labour supply is assumed to be inelastic. Each unit of labour is paid a perfectly competitive salary, $w_{t}$, expressed in terms of the good produced in the economy. The salary is partly consumed, and partly saved by young agents. Savings are expressed either in form of self-funding of physical investment activity related to individual production, or deposits issued by financial intermediaries (if any exist).

Production is carried out either by individuals (home-production) or firms. In any case, producers operate in a perfectly competitive fashion. Individuals have access to a this safe production function:

$$
Y_{t}=\psi A_{t} K_{t}^{\alpha} l_{t}^{1-\alpha}
$$

where, $Y_{t}$ is the output that can be produced by a single agent combining accumulated physical capital $K_{t}$, and labour, $l_{t}, \psi>0$ is an exogenous productivity parameter, and $A_{t}$ is an externality effect associated with the process of capital accumulation, which takes the standard form, $A_{t}=k_{t}^{1-\alpha}$, with $k_{t}=\frac{K_{t}}{l_{t}}$.

\footnotetext{
${ }^{5}$ All the way through the paper we assume the case of a logarithmic utility function (i.e. $\gamma=0$ ), although we would refer occasionally to the more general case of $\gamma \geq 0$. None of the results depends on this assumption which is meant only to simplify the analysis.
} 
Individuals engaged in production activity behave according to the perfect competition scheme. Accumulation of physical capital necessary requires one period. Therefore, individuals invest in safe production when young, hiring labour and producing when old.

Firms have access to the following risky production function:

$$
Y_{t}=\phi A_{t}\left(\pi K_{t}\right)^{\beta} l_{t}^{1-\beta}
$$

Two main differences characterise (2.3) with respect to (2.2): $i$. the presence of the new term, $\pi$, which is a time-invariant stochastic productivity shock which is equal to 1 with probability $p$, and to 0 with probability $1-p$; ii. the parameters $\phi$, and $\beta$, which are assumed to be different from $\psi$, and $\alpha$. In particular, we assume that $p \phi>\psi$, as well as $p \beta \phi>\alpha \psi$ and $p(1-\beta) \phi>(1-\alpha) \psi$, which ensure that: $i$. total expected productivity of the risky technology is higher than that of the safe; $i i$. returns on both labour and capital are higher under the risky technology than under the safe for any given level of capital per unit of labour. As in the for the safe technology, physical capital accumulation requires one period. Resolution of uncertainty about the productivity of capital takes place at the beginning of the period after investment took place. Therefore, firms' investment is a risky activity. Note that firms have no capital endowment, so that they operate if and only if they are externally funded. In the model, external financing takes the form of lending by financial intermediaries, which in turn fund themselves issuing deposit contracts, as explained in the following subsection.

Finally, full depreciation of capital is assumed both for firms', and individuals' production.

\subsection{Financial Sector}

We assume the technology associated with lending implies economies of scale. Therefore, according to standard transaction cost theory, savers willing to fund firms' investment activity have incentive to delegate the lending-task to an intermediary, which pools savings through deposit contracts, and uses the proceedings to fund firms. As a side remark we note that, given the structure of the model, the existence of a delegated-scheme can be justified also on the grounds of asymmetric information between borrowers and lenders although there is not need to introduce this explicitly. ${ }^{6}$ As fully described later on, we couple the existence

\footnotetext{
${ }^{6}$ Assume that only the borrower knows the return on investment projects he operates without incurring some cost. This implies the existence of an ex post verification problem for lenders
} 
of economies to scale in financial transactions, with economies to specialization. This provides a justification for the co-existence of more than one large size intermediary operating in the deposit-credit market. ${ }^{7}$

\section{Agents' behaviour}

\subsection{Firms}

At each time $t$ each firm demands loans to finance investments in physical capital, and, in the following period, if physical investment turns out to be successful, demands labour to run production. Perfect competition ensures both the wage workers are paid, $w_{t}$, and the rate of return paid to lenders, $R_{t}^{l}$, are equal to marginal productivity of labour, and capital respectively,

$$
\begin{aligned}
& w_{t}=(1-\beta) \phi k_{t}^{\beta} A_{t} \\
& R_{t}^{l}=\alpha \psi k_{t}^{\beta-1} A_{t} .
\end{aligned}
$$

\subsection{Consumers}

For each individual of generation $t$, period 1 consumption, $c_{1, t}$, is given by labour income, $w_{t}$, minus savings, $s_{t}$. Savings are either in form of self-financing of investment in the safe technology, $e_{t}$, or deposits, $d_{t}$, so that we write $c_{1, t}=$ $w_{t}-e_{t}-d_{t}$. Period 2 consumption, which depends on saving decisions, has this general expression,

$$
c_{2, t}=A_{t} \psi K_{t+1}^{\alpha} l_{t+1}^{1-\alpha}-w_{t+1} l_{t+1}+R_{t}^{d} d_{t}
$$

which raises the need for lenders either to monitor the borrowers or to make them sign standard debt contracts with non pecuniary losses. Assume monitoring costs imply economies to scale. A large number of risky-independent investment projects exists, in fact a continuum of mass $H$. Therefore, provided that costs associated with the non-convex monitoring technology are not too high, the standard argument produced by Diamond (1984) applies according to which delegated monitoring provides the more efficient financial superstructure. Actually, since the financial intermediary funds a continuum of projects with i.i.d returns, it can commit itself to fixed deterministic repayments to depositors. We are therefore in the limit case of Diamond's model where delegation costs are equal to zero, and the return on deposits is entirely safe.

${ }^{7}$ Note that the coexistence of financial intermediaries due to the existence of economies to specialization, is perfectly sustainable since we assume the existence of a continuum of firms. In fact, this implies that each portion of the entire population of firms has the same potential for riks diversification as the total population itself. 
according to which, if the individual runs production, then $c_{2, t}$ is given by the outcome of the production process, $A_{t} \psi K_{t+1}^{\alpha} l_{t+1}^{1-\alpha}$, minus the cost of labour, $w_{t+1} l_{t+1} .{ }^{8}$ If, on the other hand, the individual saves in form of deposits, $c_{2, t}$ will be just equal to overall return associated with deposits, ${ }^{9} R_{t}^{d} d_{t}$, where $R_{t}^{d}$ is the gross return per unit of deposit.

Young individuals choose $e_{t}$ and $d_{t}$, as well as the amount of labour to hire in their second period of life, $l_{t+1}^{d},{ }^{10}$ in order to maximise life-time utility:

$$
\max _{\left\{d_{t}, e_{t}, l_{t+1}^{d}\right\}} E\left(u_{t}\right)=\frac{c_{1, t}^{\gamma}-1}{\gamma}+\frac{1}{1+\rho} \frac{c_{2, t}^{\gamma}-1}{\gamma},
$$

where $K_{t+1}=e_{t}$. Assuming $\gamma=0$, the set of first order condition would be as follows: ${ }^{1112}$

$$
\begin{aligned}
\left(d_{t}^{*}\right) & : \frac{1}{c_{1, t}^{*}} \geq R_{t}^{d} \frac{1}{1+\rho} \frac{1}{c_{2, t}^{*}} \\
\left(e_{t}^{*}\right) & : \frac{1}{c_{1, t}^{*}} \geq \frac{1}{(1+\rho)} \frac{1}{c_{2, t}^{*}} A_{t+1} \psi \alpha k_{t+1}^{\alpha-1} \\
\left(l_{t+1}^{d *}\right) & : \frac{1}{(1+\rho)} \frac{1}{c_{2, t}^{*}}\left[(1-\alpha) \psi A_{t+1} K_{t+1}^{\alpha} l_{t+1}^{d-\alpha}-w_{t+1}\right] \leq 0
\end{aligned}
$$

Note that, in all subsequent analysis we drop the $*$ in order to simplify notation.

\subsubsection{Demand of deposits versus individual production}

From the solution of (3.4) it follows,

\footnotetext{
${ }^{8}$ In this case $d_{t}=0 \Rightarrow R_{t}^{d} d_{t}=0$.

${ }^{9}$ In this case the indidivual does not run production so that the first two elements of the RHS of (3.3) are both equal to zero.

${ }^{10} \mathrm{Of}$ course the decision about $l_{t}^{d}$ is relevant if and only if the individual engages in production.

${ }^{11}$ Each of the weak inequalities hold as a strict equality if the corresponding maximizing variable has an optimal level different from zero, and as a strict inequality, otherwise.

${ }^{12}$ Note that:

$$
\begin{aligned}
c_{t}^{*} & =w_{t}-s_{t}^{*} \\
s_{t}^{*} & =e_{t}^{*}+d_{t}^{*} \\
c_{t}^{2} & =A_{t} \psi\left(e_{t}^{*}+d_{t}\right)^{\alpha} l_{t+1}^{* 1-\alpha}-w_{t+1} l_{t+1}^{*}+R_{t}^{d} d_{t}^{*} .
\end{aligned}
$$
}


Result 1. In equilibrium, if $\psi \alpha>(<) R_{t}^{d}$ holds, agents save only via investment in safe production (deposits). Whenever $\psi \alpha=R_{t}^{d}$ they are indifferent.

Proof. In equilibrium, considering $A_{t}=k_{t}$, the optimality conditions relative to the choice of $e_{t}^{*}$ and $d_{t}^{*}$ (see equations (3.5), and (3.6), respectively), becomes

$$
\begin{aligned}
& \frac{1}{\left(w_{t}-e_{t}-d_{t}\right)} \geq \frac{\alpha \psi}{1+\rho} \frac{1}{\left(\alpha \psi e_{t}+R_{t}^{d} d_{t}\right)} \\
& \frac{1}{\left(w_{t}-e_{t}-d_{t}\right)} \geq \frac{R_{t}^{d}}{1+\rho} \frac{1}{\alpha \psi e_{t}+R_{t}^{d} d_{t}}
\end{aligned}
$$

where $\alpha \psi$ is the equilibrium rate of return on capital in case of self production. Assume, $e_{t}=0, d_{t}>0$ holds (FI). This requires

$$
\frac{\alpha \psi}{1+\rho} \frac{1}{\left(R_{t}^{d} d_{t}\right)}<\frac{R_{t}^{d}}{1+\rho} \frac{1}{R_{t}^{d} d_{t}},
$$

which in turns implies $\frac{\alpha \psi}{R_{t}^{d}}<1$. If the reverse condition holds, then $e_{t}>0, d_{t}=0$, would be optimal. Finally if $\frac{\alpha \psi}{R_{t}^{d}}=1$ holds, then individuals are indifferent between deposits and self financing

According to Result 1, individuals' decisions result generally into two possible different financial regimes:

i. Financial autarky (FA). Individuals save only through self-financing $\left(e_{t}>\right.$ $0, d_{t}=0, \Rightarrow s_{t}^{*}=e_{t}^{*}$. Note that, in this case, $K_{t+1}=e_{t}^{*}$ holds.

ii. Financial intermediation (FI). Individuals save only via deposits, $\left(e_{t}^{*}=\right.$ $0, d_{t}^{*}>0, \Rightarrow s_{t}^{*}=d_{t}^{*}$. Financial intermediaries pool all savings, and fund firms. In this case, investment is funded only via external finance in forms of loans, $K_{t+1}=b_{t} \cdot{ }^{13}$

\footnotetext{
${ }^{13}$ Note that in the peculiar case in which $\frac{\alpha \psi}{R_{t}^{d}}=1$, holds there is a third possibility, which is that agents save partly through deposits and partly through self financing. In fact if the rate of return is the same across saving opportunities, so that any combination of i. and ii. is optimal. In this case the composition of savings is indeterminated. As explained later this peculiar case does not play a major role in the analysis.
} 


\section{The economy under financial autarky}

Under financial autarky each individual saves in form of self-investment in production according to $(2.2)$, [i.e. $e_{t}>0, d_{t}=0$ ]. Therefore, firms do not operate. From the first order condition relative to the choice of $e_{t}$ (equation (3.6)) we have $e_{t}=s^{F A} w_{t}$ where $s^{F A}=\frac{1}{2+\rho}$ is the saving rate. ${ }^{14}$ From equation (3.7)) we have $w_{t}=(1-\alpha) \psi A_{t} k_{t}^{\alpha}$.

Long-Run Growth. At each time $t$, the equilibrium of the economy is given by the solution to this system:

$$
\begin{aligned}
A_{t} & =k_{t}^{1-\alpha} \\
w_{t} & =(1-\alpha) \psi A_{t} k_{t}^{\alpha} \\
s_{t} & =w_{t} s_{F A} \\
k_{t+1} & =s_{t} .
\end{aligned}
$$

The first equation refers to the externality associated with capital accumulation. The second one gives the equilibrium level of wages. The third is the microeonomic saving function and, the final equation describes the equilibrium in the market for capital: period $t+1$ capital per firm, $K_{t+1}=k_{t+1},{ }^{15}$ equals period $t$ individual savings. System (4.1) generates the equilibrium value of $k_{t+1}$, as a function of $k_{t}$ :

$$
k_{t+1}=k_{t}[\psi(1-\alpha)] s_{F A},
$$

which implies

$$
g_{F A}=\frac{k_{t+1}-k_{t}}{k_{t}}=s_{F A} \psi(1-\alpha)-1,
$$

where $g_{F A}$ is the growth rate under financial autarky. ${ }^{16}$

\footnotetext{
${ }^{14}$ from equation (3.6) we have:

$$
\frac{1}{w_{t}-e_{t}}=\frac{p}{(1+\rho) e_{t}}
$$

which leads to $e_{t}=\frac{1}{2+\rho} w_{t}$.

${ }^{15}$ Note that, in equilibrium, each individual hires one unit of labour so that $k_{t+1}=K_{t+1}$.

${ }^{16}$ Note that, since in equilibrium, $y_{t}=\psi k_{t}$, the growth rate of output is the same as the growth rate of the stock of capital per head.
} 


\section{The economy under financial intermediation}

This section describes the macroeconomic equilibrium associated with the existence of a credit market in which financial intermediaries operate pooling all savings and funding firms' investments. We refer to such equilibria as financial intermediation (FI) equilibria. In the following analysis we identify the set of supply-side conditions necessary for the existence of a FI equilibrium. Matching these conditions with the demand-side ones described in the previous section allows us to characterise the process of emergence of a credit market, as well as its subsequent evolution, and impact on economic development.

\subsection{Demand for deposits and demand for loans}

According to Result 1, whenever the intermediaries are able to guarantee an interest rate on deposits, $R_{t}^{d}$ such that $\frac{\alpha \psi}{R_{t}^{d}}<1$, deposits strongly dominate self financing, so that individual's savings will be in form of deposits. Then, the first order condition relating to the choice of savings in form of deposits, $d_{t}$ (see equation (3.5)), directly implies, $d_{t}=s_{F I} w_{t}$, where $s_{F I}=\frac{1}{2+\rho}$ is the saving rate. ${ }^{17}$

Demand for loans by the single firm, as derived from equation (3.1), is

$$
k_{t+1}=b_{t}=\left[\frac{\beta \phi A_{t}}{R_{t}^{l}}\right]^{\frac{1}{1-\beta}} .
$$

\subsection{Credit market structure}

Non-convexities associated with the lending technology imply the credit market has a non perfectly competitive structure. Moreover, as we already mentioned, we allow for another source of banks market-power, which is the existence of economies of specialisation. This generates the possibility of a credit market in

\footnotetext{
${ }^{17}$ From equation (3.5) we get:

$$
\frac{1}{w_{t}-d_{t}}=\frac{1}{1+\rho} \frac{1}{d_{t}}
$$
}

which implies $d_{t}=\frac{1}{2+\rho} w_{t}$. It is worth noting that the saving rate is the same as under financial autarky. This is due to the log-linear specification. As, theory suggests, effects of financial intermediation on saving rates are ambiguous, which is confirmed by empirical evidence [see Pagano (1993)]. Therefore, we regard as particularly appropiate the choice of a log-linear specification. In fact, this assumption allows us to derive results which are independent on the effect of financial development on the saving rate. However, we also stress, that none of results crucially depends on this specific assumption. 
which more than one financial intermediary operates. More specifically, the structure of the credit market is modelled according to a model of spatial monopolistic competition. Regarding the terminology used in the following discussion, as a matter of simplicity, we will use the terms banks for financial intermediaries, and banking sector and intermediation sector, interchangeably.

We assume the continuum of firms demanding external financial resources to be uniformly distributed on the circumference of a circle with length $H .{ }^{18}$ Firms cannot change their location. Each bank has one single location in the circle. As already explained, each bank funds itself issuing deposit contracts to savers, and funds potential investors.

Banks operate according to a non-convex lending technology, which implies consumption of a fixed amount of physical resources, $E$, plus a fraction $c<1$ per unit of allocated loans, in each period. The existence of economies to specialisation is modelled assuming,

$$
c^{\prime}(z)>o, \text { with }, \lim _{z \rightarrow 0^{+}} c^{\prime}(z)=0, \text { and } \lim _{z \rightarrow 0^{+}} c(z)=\bar{c}
$$

where $z_{t}$ is the distance between the financial intermediary and the firm. The closer is a firm to a particular bank the higher is the cost advantage of this particular bank with respect to the other banks. An implication of this assumption is that, as we will show later, as the number of banks increase inducing inter-bank competition, each bank is forced to specialize its behaviour, thereby becoming more cost-efficient.

The balance sheet describing sources and uses of funds for each bank operating on a share of the loan market equal to $z_{t}$ is as follows:

$$
D_{t}=\int_{0}^{z_{t}} b_{t} d z+\int_{0}^{z_{t}} c(z) b_{t} d z+E
$$

where $D_{t}$ are deposits pooled by the bank, $\int_{0}^{z_{t}} b_{t} d z$ is aggregate loans, $\int_{0}^{z_{t}} c(z) b_{t} d z$ is aggregate variable consumption of resources due to monitoring costs, and $E$ is fixed consumption of resources. Banks act as price takers in the market for deposits. Therefore, each bank takes as given the deposit contract to be offered to savers, This contract implies the payment of a safe gross interest rate $R_{t}^{d} \cdot{ }^{19}$

\footnotetext{
${ }^{18}$ This spatial nature of the model could be interpreted literally. If so a point in the circle could be either interpreted as a physical location, or as one of the economy's sectors. However, the characteristics space could also be given a location-free interpretation in terms of differentiation of other product attributes.

${ }^{19}$ Note that banks are able to commit themselves to fixed safe repayment on deposits be-
} 


\subsubsection{Bank behaviour}

Profits of each bank can be written as:

$$
\pi_{t}=\int_{0}^{z_{t}} p R_{t}^{l} b_{t}\left(R_{t}^{l}\right) d z-R_{t}^{d} D_{t}
$$

According to this equation, profits are given by total expected revenues, $2 \int_{0}^{z} p R_{t}^{l} b^{d}\left(R_{t}^{l}\right)$, minus costs associated with deposits, $R_{t}^{d} D_{t}$. Substituting for $d_{t}$ and $b_{t}=b_{t}\left(R_{t}^{l}\right)$ according to equations (5.2), and (5.1), respectively, into the profit expression we get:

$$
\pi_{t}=2 \int_{0}^{z_{t}}\left\{p R_{t}^{l}-[1+c(z)] R_{t}^{d}\right\} d z l_{t}\left(\frac{\alpha \psi A_{t+1}}{R_{t}^{l}}\right)^{\frac{1}{1-\beta}}-R_{t}^{d} E .
$$

Each bank $i$ selects the level of $R_{t}^{l, i}$ and $z_{t}^{i}$ which maximize profits. Note that we do not allow for any degree of price discrimination in the loan market. This is because we assume that firms located along the circle look ex ante as identical to the bank. The bank knows that ex-post some firms will be more "distant", and therefore costly to serve than others, but ex-ante it cannot discriminate among them. ${ }^{20}$ This maximisation problem faced by a generic bank $i$ is subject to the following constraint on the market share $\left(z_{t}^{i}\right)$ :

$$
z_{t}^{i} \leq\left\{\begin{array}{l}
H \text { if } R_{t}^{l, i}<\bar{R}_{t}^{l, j} \\
H-2 \sum_{j}^{n_{t}-1} \bar{z}_{t}^{j} \text { if } R_{t}^{l, i}>\bar{R}_{t}^{l, j} \\
H-\sum_{j}^{n_{t}-1} \bar{z}_{t}^{j} \text { if } R_{t}^{l, i}=\bar{R}_{t}^{l, j}
\end{array}\right.
$$

where, $R_{t}^{l, i}$ is the interest rate on loans charged by the bank, is $H$ is the overall size of the market, $n_{t}$ is the number of banks, $\bar{z}_{t}^{j}$, and $\bar{R}_{t}^{l, j}$ are the market share

cause they are funding a continuum of identical risk independent project which enables them to completely diversify risks associated with loans.

${ }^{20}$ The intuition for this assumption is that intermediation costs associated with a specific firm are, to a great extent, the result of the evolution of the relationship between the firm and the bank subsequent to the "funding stage". As long as the pattern of this evolution is predictable a priori, the bank is not able to predict financial intermediation costs associated with a specific firm. Having said that, it has to be said that this particular assumption is an innoquous one. Introducing full price discrimination would imply an equilibrium whose properties are similar to those of the one we derive, and moreover entirely consistent with all the results in the paper. For an example of the full discrimination approach see Sussman (1993). 
and the interest rate on loans charged by the other competitors. ${ }^{21}$ The bank $i$ takes $n_{t}$ as well as $\bar{z}_{t}^{j}$, and $\bar{R}_{t}^{j}$ as given. The maximisation problem faced by each bank can be written as follows:

$$
\begin{aligned}
\max _{\left\{R_{t}^{l}, z_{t}\right\}} \pi_{t}= & 2 \int_{0}^{z_{t}}\left\{p R_{t}^{l}-[1+c(z)] R_{t}^{d}\right\} d z l_{t}\left(\frac{\alpha \psi A_{t+1}}{R_{t}^{l}}\right)^{\frac{1}{1-\beta}}-R_{t}^{d} E \\
& \text { s.to }(5.4)
\end{aligned}
$$

The first order conditions associated with the solution of the above maximisation problem $^{22}$ imply:

$$
\begin{aligned}
R_{t}^{l} & =\frac{\int_{0}^{z_{t}}[1+c(z)] d z}{\beta p z_{t}} R_{t}^{d}, \\
\left\{p R_{t}^{l}-\left[\left(1+c\left(z_{t}\right)\right)\right]\right\} R_{t}^{d} & =\lambda,
\end{aligned}
$$

where the Lagrangean multiplier $\lambda$ is equal to zero if (5.4) is satisfied as strict inequality, and positive otherwise.

\subsection{Loans market equilibrium}

We focus on symmetric equilibria. A symmetric equilibria implies optimal values for the decision variables such that: $z_{t}^{j}=z_{t}^{i}, R_{t}^{l, j}=R_{t}^{l, i}$, for any $i \neq j$. Two possible cases emerge, $(i i)$ and $(i)$, depending on the market's share constraint $z_{t}^{j}+z_{t}^{i} \leq \frac{H}{n_{t}}$, being binding $(i i)$ or not $(i)$.

i. Local monopolists case. In this case $z_{t}^{j}=z_{t}^{i}=z^{m} \leq \frac{H}{2 n_{t}}$ for any $i \neq j$, where $z^{m}$ is the share of the market served by each bank operating as a

\footnotetext{
${ }^{21}$ Expression (5.4) describes a standard feasibility constraint. In order for the market share selected by each of the $n_{t}$ operating banks to be feasible the sum of the market shares has to be not greater than the entire market. This constraint is the origin of strategic interaction among firms.

${ }^{22}$ The two first order conditions are:
}

$$
\begin{aligned}
\left(R_{t}^{l}\right) \quad: & -p z_{t} \beta+\int_{0}^{z_{t}}[1+c(z)] d z \frac{R_{t}^{d}}{R_{t}^{l}}=0 \\
\left(z_{t}\right) & : \quad R_{t}^{l} p-\left[\left(1+c\left(z_{t}\right)\right)\right] R_{t}^{d}=\lambda .
\end{aligned}
$$


monopolist. Note that this equilibrium is feasible if and only if $z^{m} \leq \frac{H}{2 n_{t}}{ }^{23}$ More precisely, in this situation each bank sets a combination of the market share, $z^{m}$, and the gross interest rate on loans, $R_{t}^{l}$, such that:

$$
\begin{aligned}
& R_{t}^{l}=\frac{\int_{0}^{z^{m}}[1+c(z)] d z}{\beta p z^{m}} R_{t}^{d}, \\
& \text { and, } \\
& \frac{\int_{0}^{z^{m}}[1+c(z)] d z}{\beta z^{m}}=\left(1+c\left(z_{t}^{m}\right)\right),
\end{aligned}
$$

hold simultaneously. Since all banks are identical, symmetry implies that the optimal combination of $R_{t}^{l}$ and $z^{m}$ will be the same for all banks.

ii. Competition among banks. This is the case whenever $z^{m}>\frac{H}{2 n_{t}}$. In this case a conjectured symmetric Nash equilibrium would be:

$$
\begin{aligned}
z_{t}^{j} & =z_{t}^{i}=z_{t}=\frac{H}{2 n_{t}}<z^{m} \\
R_{t}^{l} & =\frac{\int_{0}^{\frac{H}{2 n_{t}}}[1+c(z)] d z}{\beta p \frac{H}{2 n_{t}}} R_{t}^{d},
\end{aligned}
$$

for any pair of banks, $j$ and $i$. To confirm that this situation corresponds to a Nash equilibria, we analyse if a single bank $i$ would benefit from deviating. Deviation implies setting either $R_{t}^{l, i}$ or $z_{t}^{i}$ or both different from the values specified above. It is clear that any attempt by the bank to set $R_{t}^{l, i}>R_{t}^{l}$ would be frustrated. The bank would serve only a market share equal to $\frac{H}{2 n_{t}}$, at an higher interest rate which is sub-optimal. ${ }^{24}$ Assume then that the firm seeks an higher value of $z_{t}$, for instance $z^{m}>\frac{H}{2 n_{t}}$, leaving unchanged $R_{t}^{l}$. Note that, taking as given other banks' actions, the bank can achieve $z^{m}$ as long as $z^{m}<H-\sum_{j}^{n_{t}-1} \bar{z}_{t}^{j}$. Assuming this is convenient for bank $i$, competitors would reply in the same way so that at the end the equilibrium would imply again $z_{t}=\frac{H}{2 n_{t}}$. Finally, the bank might decide to set

\footnotetext{
${ }^{23}$ Whenever the reverse is true, $2 n_{t} z^{m}>H$ follows, which is not feasible since the size market served by the $n_{t}$ banks, $2 n_{t} z^{m}$ cannot be greater than the overall size of the market, $H$.

${ }^{24}$ If $R_{t}^{l, i}>R_{t}^{l}$ then no one of the firms located between $z^{m}$ and $\frac{H}{2 n_{t}}$ will demand loans from the bank. Bank $i$ will then serve a share $\frac{H}{2 n_{t}}$ at the higher interest rate. Therefore, the actual share served by bank $i$ would be $z_{t}=\frac{H}{2 n_{t}}$. If so, bank $i$ is not behaving optimally because the interest rate is too high than the maximising one.
} 
a lower value of $R_{t}^{l}$ and a lower value of $z_{t}$ but this strategy gives lower profits than the optimal one since profits are an increasing function of $z_{t}$. So finally, the conjectured Nash equilibrium turns out to be the only equilibrium of the game.

Substituting the optimal value of $R_{t}^{l}$, and $z_{t}$ into the profit equation (5.3) we get:

$$
\pi_{t}^{E}=2 R_{t}^{d} \int_{0}^{z_{t}}[1+c(z)] d z\left(\frac{1}{\beta}-1\right) b_{t}-R_{t}^{d} E .
$$

Banks face potential competition. Potential competitors have an incentive to enter the credit market if and only if they can make positive profits. Therefore, in order for the credit market to be in equilibrium, i.e. in order to have an equilibrium number of banks, the following condition has to hold for some finite value of $n_{t}^{*}>0$ :

$$
\pi_{t}^{E}=0 .
$$

At this stage potential new competitors have no incentive to enter the market. Notice that the equilibrium condition is expressed as a strict equality only because we measure the number of banks as a continuous variable, i.e. we disregard the fact that $n_{t}$ is an integer, an assumption which is made only to simplify the exposition. Both stability, and existence of this equilibrium are analysed in the following subsection.

\subsection{Macroeconomic equilibrium}

Given banks' and individuals' behaviour, the following relationships hold for $R_{t}^{l}$ (the rate of return on loans), and $R_{t}^{d}$ (the rate of return on deposits):

$$
\begin{gathered}
R_{t}^{l}=A_{t+1} \phi \beta k_{t+1}^{\beta-1} \\
R_{t}^{d}=\frac{p \phi \beta^{2} A_{t+1} k_{t+1}^{\beta-1}}{\frac{\int_{0}^{z_{t}}[1+c(z)] d z}{z_{t}}},
\end{gathered}
$$

where the expression for the interest rate on deposits is found by combining equations (5.6), and (5.9). Then, recalling that

$$
w_{t+1}=(1-\beta) \psi A_{t+1} k_{t+1}^{\beta} .
$$

and given $A_{t+1}=k_{t+1}^{1-\alpha_{R}}$ we have 


$$
\begin{aligned}
R_{t}^{d} & =\frac{p \phi \beta^{2}}{\frac{\int_{0}^{z_{t}}[1+c(z)] d z}{z_{t}}} \\
R_{t}^{l} & =\psi \beta \\
w_{t+1} & =(1-\beta) \phi k_{t+1} .
\end{aligned}
$$

Turning to the credit market flows of funds, we note that, in equilibrium, the number of firms operating at time $t$ can be written as $f=\min \left(H, 2 n_{t} z^{m}\right),{ }^{25}$ so that, $l_{t+1}=\frac{H}{p f},{ }^{26}$ and $b_{t+1}=\frac{H}{p f} k_{t+1},{ }^{27}$ follow. Moreover, in equilibrium, aggregate deposits, $H D_{t}=H s^{F I} w_{t}=H s^{F I}(1-\beta) \phi k_{t}$, have to be equal to uses of funds (i.e. loans plus consumption of resources) made by the $n_{t}$ operating banks. Therefore, using equation (5.2), the aggregate balance sheet equation for the credit market can be written as: ${ }^{28}$

$$
H s^{F I}(1-\beta) \phi k_{t}=\left[2 n_{t} \int_{0}^{z_{t}} d z+2 n_{t} \int_{0}^{z_{t}} c(z) d z\right] \frac{H}{p f} k_{t+1}+n_{t} E,
$$

which implies

$$
k_{t+1}=\frac{p f\left[s^{F I}(1-\beta) \phi k_{t}-n_{t} \frac{E}{H}\right]}{2 n_{t} \int_{0}^{z_{t}}[1+c(z)] d z} .
$$

\footnotetext{
${ }^{25}$ Firms are uniformally distributed along the circle of length $H$. Whenever $n_{t}^{m}$ banks operate as local monopolists, each serving a market share equal to $z^{m}$, the total share of the market served by these intermediaries is $2 n_{t} z^{m} \leq H$. This is also the mass of firms served by banks. Firms, in the space $H-2 n_{t}^{m} z^{m}$ are not served. Whenever bank compete each other, all the market $H$ is served, i.e. the mass of funded firms is $H$. Therefore, in general, $f=\min \left[2 n_{t} z^{m}, H\right]$ holds.

${ }^{26}$ In equilibrium the amount of labour hired by each firm, $l_{t+1}$, is equal to the aggregate mass of labour $H$ divided by the mass of successful firms, $p f$.

${ }^{27}$ Note that, given, $A_{t+1}=k_{t+1}^{1-\beta}$, and $R_{t}^{l}=\alpha \psi, b_{t}\left(R_{t}^{l}\right)=l_{t+1}\left(\frac{\beta \phi A_{t+1}}{R_{t}^{l}}\right)^{\frac{1}{1-\beta}}$ reduces to $l_{t+1} k_{t+1}=\frac{H}{p f} k_{t+1}$.

${ }^{28}$ Formally, aggregating the balance sheet equation (see equation (5.2)) across banks we get

$$
H s^{F I}(1-\beta) \phi k_{t}=2 n_{t} \int_{0}^{z_{t}} b_{t} d z+2 n_{t} \int_{0}^{z_{t}} c(z) b_{t} d z+n_{t} E,
$$

where $2 n_{t} \int_{0}^{z_{t}} b_{t} d z$ is aggregate loans, and $2 n_{t} \int_{0}^{z_{t}} c(z) d z b_{t}+n_{t} E$ is aggregate consumption of resources by the credit sector.
} 
Finally, free entry in the credit market implies that, in equilibrium, per bank profit should be equal to zero. Imposing this condition implies

$$
2 R_{t}^{d} \int_{0}^{z_{t}}[1+c(z)] d z\left(\frac{1}{\beta}-1\right) b_{t}=R_{t}^{d} E .
$$

From which follows that the equilibrium number of banks is ${ }^{29}$

$$
\begin{aligned}
n_{t} & =\zeta k_{t}, \\
\text { with } \zeta & =\frac{H\left[(1-\beta)^{2} \phi s^{F I}\right.}{E}
\end{aligned}
$$

Note that equation (5.14) describes the equilibrium relationship between number of banks and level of economic development when the economy is already operating under financial intermediation, i.e. when savings are determined according to wages paid by firms producing according to the risky technology. This relationship is therefore different from that which characterised the economy during the period of transition from financial autarky to financial intermediation analysed in the following subsection.

The macroeconomic equilibrium of the economy operating under FI is therefore completely described as follows:

$$
\begin{aligned}
g_{t}^{F I} & =\frac{p f\left[s^{F I}(1-\beta) \phi-n_{t} \frac{E}{k_{t} H}\right]}{2 n_{t} \int_{0}^{z t}[1+c(z)] d z} \\
n_{t} & =\zeta k_{t} \\
\text { with } z_{t} & =\min \left[z^{m}, \frac{H}{2 n_{t}}\right], \text { and } f=\min \left[H, 2 n_{t} z^{m}\right]
\end{aligned}
$$

\section{Financial and economic development}

In this section we bring together the demand/supply conditions relative to deposits and loans to analyse both the endogenous emergence and subsequent development

\footnotetext{
${ }^{29}$ Substituting for $b_{t}=k_{t+1} \frac{H}{f p}$, and using the above expression for $k_{t+1}$ we have:

$$
\left(\frac{1}{\alpha}-1\right) \frac{H\left[s^{F I}(1-\beta) \phi k_{t}-n_{t} \frac{E}{H}\right]}{n_{t}}=E,
$$
}

which leads to (5.14). 
of the credit market, and the consequences of this for the process of economic development.

\subsection{Emergence of the credit market and its subsequent evolution}

In order for a financial intermediation equilibria to emerge the necessary and sufficient conditions to be satisfied are:

$i$. the equilibrium rate of return to deposits, $R_{t}^{d}$, satisfies $\frac{\alpha \psi}{R_{t}^{d}}<1$ (demand condition, see Result 1);

ii. an equilibrium number of banks $n_{t} \geq 1$ exists (supply condition).

Regarding point $i$, we know that, in equilibrium,

$$
\begin{aligned}
R_{t}^{d} & =\frac{p \psi \beta^{2}}{\frac{\int_{0}^{z t}[1+c(z)] d z}{z_{t}}}, \\
\text { with } z_{t} & =\min \left\{z^{m}, \frac{H}{2 n_{t}}\right\}
\end{aligned}
$$

Suppose that banks operate as local monopolists. Then, as previous analysis suggests $z_{t}$ should be equal to $z^{m}$ which is associated with the unconstraint optimal level of profits. This is indeed the case if the equilibrium rate of return on deposits associated with $z^{m}$, call it $R_{m}^{d},{ }^{30}$, is such that $R^{d, m} \geq \psi \alpha$ hold so that individuals would prefer saving in form of deposits. If this is not the case, then, in equilibrium, banks operating as local monopolists would be constraint to operate a level of $z_{t}$, call it $\bar{z}$, such that $R_{\bar{z}}^{d}=\psi \alpha$. Note that, since $R_{t}^{d}$ is decreasing in $z_{t}$, $\bar{z}<z^{m}$ holds. ${ }^{31}$ Having said that, we assume, without any loss of generality, that

${ }^{30}$ where,

$$
R_{m}^{d}=\frac{p \phi \beta^{2}}{\frac{\int_{0}^{z_{m}}[1+c(z)] d z}{z_{m}}}
$$

${ }^{31}$ From (5.11) we have,

$$
\frac{d R_{t}^{d}}{d z_{t}}=p \phi \beta^{2} \frac{\frac{\int_{0}^{\frac{H}{2 \zeta^{T} k_{t}}}}{1}[1+c(z)] d z-\left[1+c\left(z_{t}\right)\right] z_{t}}{\left(\int_{0}^{\frac{H}{2 \zeta^{T} k_{t}}}[1+c(z)] d z\right)^{2}}
$$


$R^{d, m} \geq \alpha \psi$ so that the unconstraint optimal level of market share chosen by local monopolists does guarantees the existence of a financial equilibrium. ${ }^{32}$ Finally, since $R_{t}^{d}$ is decreasing in $z_{t}, R_{t}^{d} \geq \alpha \psi$ follows for any $z_{t}=\min \left\{z^{m}, \frac{H}{2 n_{t}}\right\}$. Therefore, the demand side condition necessary for the existence of a FI equilibria is automatically satisfied since $z_{t}=\min \left\{z^{m}, \frac{H}{2 n_{t}}\right\}$ is always true in FI equilibria. Regarding $i$, assume that the economy is initially under financial autarky. Then, given a capital stock $k_{t}$, the aggregate level of savings potentially channelled to the banking sector in form of deposits are, $H s^{F A}(1-\alpha) \psi k_{t}$. To this quantity of deposits it is associated an equilibrium number of banks which could operate in the economy at the emergence of the credit market is, ${ }^{33}$

$$
\begin{aligned}
n_{t}^{T}= & \zeta^{T} k_{t} \\
& \text { with } \zeta^{T}=\frac{H\left[(1-\beta)(1-\psi) \psi s^{F I}\right.}{E} .
\end{aligned}
$$

It then follows,

Result 2. $i$. The economy operates under financial autarky (FA) for $k_{t}<k^{*}$; financial intermediation equilibria (FI) endogenously arise at some critical level of economic development $k_{t} \geq k^{*}$. ii. Banks could operate initially as local monopolists as long as $n^{T} \leq \frac{H}{2 z^{m}} \equiv n^{M}$. iii. Interbank competition arises for $n_{t}>n^{M}$.

Proof. A credit market emerges as long as the number of banks that could be sustained in equilibrium, $n_{t}$, is greater or equal to 1 . Since $n_{t}^{T}=\zeta^{T} k_{t}$, it follows immediately that emergence occurs as $k_{t}$ reaches $k^{*}=\frac{1}{\zeta^{T}}$. At the emergence of FI

Given $c^{\prime}\left(z_{t}\right)>0$ (economies to specialisation), the function $\int_{0}^{z_{t}}[1+c(z)] d z$ is convex in $z_{t}$. This ensures that $\int_{0}^{\frac{H}{2 \zeta^{T} k_{t}}}[1+c(z)] d z-\left[1+c\left(z_{t}\right)\right] z_{t}<0$. Therefore, $\frac{d r_{t}^{d}}{d k_{t}}>0$ holds. Finally, note that $\bar{z}>0$ exists as long as $R^{d}=\lim _{z_{t} \rightarrow 0} R_{t}^{d} \equiv \frac{p \phi \beta^{2}}{1+\bar{c}}>\alpha \psi$. If this condition does not hold, financial intermediation never develops.

${ }^{32}$ This is the case since, as we will see the number of banks operating in equilibrium does not depend on $R_{t}^{d}$.

${ }^{33}$ In the transition period

$$
\left(\frac{1}{\beta}-1\right) \frac{H\left[s^{F I}(1-\alpha) \psi k_{t}-n_{t} \frac{E}{H}\right]}{n_{t}}=E,
$$

which leads to (6.1). 
banks operating as local monopolists are feasible if and only if $n_{t}^{T} \leq \frac{H}{2 z^{m}} \equiv n^{M}$. Whenever the number of banks that are associated with the emergence of the credit market is higher than $\frac{H}{2 z^{m}}$, then banks compete against each other since the emergence. After transition, $n_{t}=\zeta k_{t}$ holds, so that the maximum number of banks operating as local monopolists that can be sustained in equilibrium is associated with $k^{M}: k^{M}=\frac{H}{2 \zeta z^{m}}$. For $k_{t}>k^{M}$, banks compete against each other and $z_{t}=\frac{H}{2 n_{t}}<z^{m}$ follows.

\subsection{Growth effects of financial development}

In this section we first of all analyse the growth impact of the transition from financial autarky to financial intermediation. Then, we move the analysis one step further analysing the non deterministic two ways causation relation between economic and financial development which characterises the model.

\subsubsection{Transition to financial intermediation}

Assume that the economy operates under financial autarky (intermediation) for $k_{t}<(>) k^{*}$. Then, transition occurs as long as $k_{t}$ reaches a value greater or equal to $k^{*}$. In the transition period the growth rate of the economy is given by

$$
\begin{aligned}
g^{T} & =\frac{\phi p}{\psi} \frac{\left[\psi(1-\alpha) s_{F I}-\frac{n_{t} E}{k_{t}}\right]}{\frac{1}{z_{t}} \int_{0}^{z_{t}}[1+c(z)] d z}-1 \\
\text { with } z_{t} & =\min \left\{z^{m}, \frac{H}{2 n_{t}}\right\}
\end{aligned}
$$

The two main effects induced by transition are:

- savings are channelled toward the more productive although risky technology;

- part of the saved resources is consumed to perform the necessary financial transactions to link households (lenders) and firms (borrowers).

While the first effect positively reflects in future growth rate, the second effect has a negative effect on the growth rate associated with the transition period. 
Proposition 1. i. Whenever $\frac{\alpha}{\beta}<1$, emergence of financial intermediation has an ambiguous impact on the growth rate of the economy during the transition from financial autarky to financial intermediation. ii. Whenever $\frac{\beta}{\alpha \psi}>\left(\frac{1-\alpha}{2+\rho}\right)^{2} \psi$, the economy could be stuck in a low development trap [see also figure (8.1)].

Proof. Using the relationship between $n_{t}$ and $k_{t}$, which characterises the economy during the transition (see equation (6.1)), together with (6.3) we can rewrite $g^{T}$ as

$$
g^{T}=\frac{\phi p}{\psi} \frac{(1-\alpha) \psi \beta s_{F I}}{\frac{1}{z_{T}} \int_{0}^{z_{T}}[1+c(z)] d z}-1 .
$$

Comparing it with the growth rate under financial autarky, yields:

$$
g^{F I} \lesseqgtr g^{F A} \Longleftrightarrow \frac{\phi p}{\psi} \frac{(1-\alpha) \psi \beta s_{F I}}{\frac{1}{z_{T}} \int_{0}^{z_{T}}[1+c(z)] d z} \lesseqgtr \psi(1-\alpha) s_{F A}
$$

which, given $s^{F I}=s^{F A}$ reduces to

$$
\frac{1}{z_{T}} \int_{0}^{z_{T}}[1+c(z)] d z \gtreqless \frac{p \phi \beta}{\psi} .
$$

So, in order for transition to have negative growth effects, consumption of resources by the financial sector has to be big enough, i.e. financial intermediaries have to be relatively inefficient. However, banks cannot be too inefficient, since the emergence of financial intermediation requires,

$$
\frac{1}{z_{T}} \int_{0}^{z_{t}}[1+c(z)] d z<\frac{\beta^{2} \phi p}{\alpha \psi} .
$$

Combining equations (6.2) and (6.3) we finally get that transition to financial intermediation has an negative impact on the growth rate of the economy, if,

$$
z_{T}: \frac{p \phi \beta}{\psi}<\frac{1}{z_{T}} \int_{0}^{z_{T}}[1+c(z)] d z<\frac{\beta^{2} \phi p}{\alpha \psi}
$$

and positive otherwise. Note that (6.4) can be satisfied for positive values of $z_{T}$ iff $\frac{\beta}{\alpha}>1$, [this completes part $i$ ].

When the growth rate in the transition period is negative, the stock of capital in the period post transition, call it $k^{T+1}$, would be lower than $k^{T}$. In principle the economy could still operate under financial intermediation. A sufficient condition for this to happen is $k^{T+1}>k^{*}$ where $k^{*}$ is defined in result 2 as the critical 
level of economic development such that financial equilibria emerge. If this is the case then, the dynamics of the economy would be as it is discussed in the next subsection. If not, the economy will fall again under financial autarky. It is crucial to note that the maximum stock of capital the economy can accumulate before switching to financial intermediation is $k^{*} g^{F A}$. Then, it follows that if the growth rate in the transition period is such that $k^{*}\left(g^{F A}+1\right)\left(g^{T}+1\right)<k^{*}$ the economy is stuck in an underdevelopment trap [see also figure 1.1]. This condition is equivalent to $\left(g^{T}+1\right)\left(g^{F A}+1\right)<1 \Rightarrow g^{T}+1<\frac{1}{g^{F A}+1}$. Substituting for $g^{F A}$ and $g^{T}$, and using $s^{F A}=s^{F I}=\frac{1}{2+\rho}$, gives

$$
\psi p \phi\left(\frac{1-\alpha}{2+\rho}\right)^{2} \beta<\frac{1}{z_{T}} \int_{0}^{z_{T}}[1+c(z)] d z .
$$

Combining this with the condition necessary for emergence, we have, that transition to financial intermediation yields negative growth, so that the economy is trapped in a low development trap, iff:

$$
z_{T}: \psi p \phi\left(\frac{1-\alpha}{2+\rho}\right)^{2} \beta<\frac{1}{z_{T}} \int_{0}^{z_{T}}[1+c(z)] d z<\frac{\beta^{2} \phi p}{\alpha \psi}
$$

which holds for positive values of $z_{T}$ if and only if $\frac{\beta}{\alpha \psi}>\left(\frac{1-\alpha}{2+\rho}\right)^{2} \psi$

Discussion. Both the ambiguity of the growth impact of emergence of a credit market and the possibility of development traps in which the economy is not able to complete the transition to financial intermediation crucially depend on the level on the product share of capital associated with the risky technology $\beta$, compared to the safe one, $\alpha$. Whenever $\frac{\beta}{\alpha}>1$ as we expect if the transition from individual to firm-based production is associated with a process of industrialisation, ${ }^{34}$ i.e. with a shift toward capital intensive technologies, the possibility of a detrimental growth effect to be associated with the emergence of a financial sector which is necessary to this transition, emerges. this leads to the extreme case of the unfeasibility of transition from financial autarky to financial intermediation, i.e. to the infeasibility of industrialisation. The economic rationale is behind this result is as follows. The higher is $\frac{\beta}{\alpha}$ the higher will be, coeteris paribus, the rate

\footnotetext{
${ }^{34}$ Hansen and Prescott (1998)

model the process of industrialisation as the shift from a production function in which reproducible capital has little importance with respect to labour, to a production process in which the role of the two output is reversed.
} 
of return on capital associated with the risky technology compared to the one associated with the safe on, and this also reflects in a higher rate of return on deposits. This implies that the higher is $\frac{\beta}{\alpha}$ the lower is the level of efficiency of financial intermediaries which is required for a financial equilibrium to exist, so that a relatively more inefficient credit market could arise. Or, in other words, financial intermediation might develop too early in order to sustain the transition from individual production to firm production.

\subsection{Post transition growth effects}

Assuming the economy completes the transition process from financial autarky to financial intermediation the relationship between economic and financial development will be the combined result of the productivity of the technology available to firms, and the degree of competition in the credit market.

Proposition 2. i. The growth rate in the post transition period $(T+1)$, can be either lower or greater than $g^{F A}$. ii. As long as the growth rate is positive, transition to financial intermediation can be completed [successful take-off, see figure (8.3)], and growth effects of subsequent financial development depend on competition in the credit market . ii. Whenever $s_{F I}(1-\beta)<\frac{\beta}{\alpha \psi}$ holds the economy could be stuck in a low development trap [unfeasible take off, see figure $(8.2]$.

Proof. (Part i). In general the growth rate in the post-transition period $T+1$ is given by

$$
g_{T+1}^{F I}=\frac{p(1-\beta) \phi \beta s_{F I}}{z_{T+1} \int_{0}^{z_{T+1}}[1+c(z)] d z}, \text { with } z_{T+1}=\min \left[z^{m}, \frac{H}{2 n_{T+1}}\right],
$$

Comparison with $g^{F A}$ yields

$$
g^{F I} \lesseqgtr g^{F A} \Leftrightarrow \frac{p(1-\beta) \phi \beta}{(1-\alpha) \psi} \lesseqgtr z_{T+1} \int_{0}^{z_{T+1}}[1+c(z)] d z .
$$

Combining this with the condition for emergence,

$$
\frac{p(1-\beta) \phi \beta}{(1-\alpha) \psi}<\frac{1}{z_{T+1}} \int_{0}^{z_{T+1}}[1+c(z)] d z<\frac{\beta^{2} \phi p}{\alpha \psi}
$$


which holds for some positive value of $z_{t}$ if and only if $\frac{\beta}{1-\beta}>\frac{\alpha}{1-\alpha} \Longleftrightarrow \frac{\beta}{\alpha}>1$ [this ends part $i$ ]. Assume banks act as local monopolists, i.e. $k^{*}<k^{M}$. Then, for any $k_{t} \in\left(k^{*}, k^{M}\right]$ the economy operates under FI with banks acting as local monopolists. Then $z_{t}=z^{m}$ so that the growth rate of the economy is constant with respect to $k_{T+1}$. Therefore further financial development induced by economic development has no effect as long as $k_{t 1}<k^{M}$. On the contrary whenever banks starts competing in market shares, $z_{t}=\frac{H}{2 n_{t}}$. At this stage we have

$$
\frac{d g_{F I, t}}{d k_{t}}=-p\left[(1-\beta) \phi s_{F I}-\zeta \frac{E}{H}\right]\left[\frac{\int_{0}^{\frac{H}{2 \zeta k_{t}}} c\left(z_{t}\right) d z_{t}-c\left(\frac{H}{\zeta k_{t}}\right) \frac{H}{\zeta k_{t}}}{\left\{1+2 \frac{\zeta k_{t}}{H} \int_{0}^{\frac{H}{\zeta k_{t}}}\left[1+c\left(z_{t}\right)\right] d z_{t}\right\}^{2}}\right] \frac{H}{\zeta k_{t}^{2}}
$$

As we already know, since $\int_{0}^{\frac{H}{\zeta k_{t}}}\left[1+c\left(z_{t}\right)\right] d z_{t}$ is a convex function in $z_{t}$ for all $k_{t} \in(o, \bar{k})$, so that this implies $\frac{d g_{F I, t}}{d k_{t}}>0$ for all $k_{t} \in(o, \infty)$. As it is the case for the rate of return on deposits, as long as the economies to specialisation are exhausted, i.e. $k_{t}$ holds, the growth rate of the economy is constant at the level

$$
\bar{g}_{F I}=\lim _{k_{t} \rightarrow \infty} g_{t}^{F I}=\frac{p\left[(1-\beta) \phi s_{F I}-\frac{\zeta E}{H}\right]}{[1+\bar{c}]} .
$$

(this ends part i). Finally, recall that

$$
g_{T+1}^{F I}=\frac{p(1-\beta) \phi \beta s_{F I}}{z_{T+1} \int_{0}^{z_{T+1}}[1+c(z)] d z}-1 .
$$

It then follows that we have negative growth whenever

$$
z_{T+1} \int_{0}^{z_{T+1}}[1+c(z)] d z>p(1-\beta) \phi \beta s_{F I}
$$

that the economy experiences negative growth under financial intermediation so that it would be eventually trapped in a low development region iff:

$$
z_{T+1}: p(1-\beta) \phi \beta s_{F I}<\frac{1}{z_{T+1}} \int_{0}^{z_{T+1}}[1+c(z)] d z<\frac{\beta^{2} \phi p}{\alpha \psi}
$$

which holds for some positive value of $z_{T+1}$ if and only if $s_{F I}(1-\beta)<\frac{\beta}{\alpha \psi}$, which completes the proof (part ii) 
Discussion. Once banks face competition, further entrance in the credit market induced by economic development, reduces the share of the market served by each bank. This, given the existence of economies to specialisation, results in a lower average variable consumption of resources associated with financial transactions. ${ }^{35}$ Therefore the flow of resources flowing to investment, is coeteris paribus, higher which affects positively the growth rate. On the other hand, an increase in the number of banks rises fixed costs associated with financial intermediation, i.e. $n_{t} E$ increases with $n_{t}$. However, the growth expression suggests this effect is more than offset by that induced by specialisation. Once again the possibility of an initially negative effect of the complete transition to financial intermediation as well the possibility of development traps depends crucially on $\frac{\beta}{\alpha}$. Again, the same interpretation discussed for the transition case applies. Whenever $\frac{\beta}{\alpha}$ is too high financial intermediation tends to develop too early and this compromise the chances of further development.

The possibility of the economy falling in a poverty trap either in the posttransition or in the transition phase from financial autarky to financial intermediation raises some comments about financial liberalisation policies. In particular, it might be observed that the successfulness of measures devoted to liberalise credit markets might depend on the ability of the country to attract foreign capital.

\subsection{Does the decentralised economy lead to an optimal level of financial intermediation activity?}

Let us define the optimal level of financial intermediation for a given level of $k_{t}$, as the number of banks that maximises the growth rate. Formally,

$$
n^{*}=\arg \max _{\left\{n_{t}\right\}} g_{t}^{F I} .
$$

Consider the case in which banks operate as local monopolists. Recall that in this case the growth rate is:

$$
g_{t}^{m}=\frac{p\left[s^{F I}(1-\beta) \phi-\frac{n_{t}^{m} E}{H k_{t}}\right]}{\frac{1}{z^{m}} \int_{0}^{z^{m}}[1+c(z)] d z}
$$

It is immediate to see that as the number of banks increases, under the hypothesis that they behave as local monopolists, this has a detrimental effect on growth. ${ }^{36}$

\footnotetext{
${ }^{35}$ Note that $2 \frac{\zeta k_{t}}{H} \int_{0}^{\frac{H}{\zeta k_{t}}}\left[c\left(z_{t}\right)\right] d z_{t}$ can be interpreted as average variable consumption of resources at an aggregate level.

${ }^{36}$ That is,
} 
Therefore, for all values of $k_{t}$ such that banks operate as "local monopolists" the optimal number of banks is $n_{t}^{*}=1$.

Result 3. Given $k_{t} \geq k^{*}$, further financial development has a detrimental effect on growth for $k_{t} \in\left[k^{*}, k^{M}\right]$.

Proof. The result follows immediately since banks operate as local monopolists for all values of $k_{t} \in\left[k^{*}, k^{M}\right]$, (see Result 2)

Result 3 refers to FI equilibria characterised by banks operating as local monopolists for $k_{t} \in\left[k^{*}, k^{M}\right]$. Consider now the case in which banks operate competing each other. In this case the growth rate is:

$$
g_{t}^{F I}=\frac{p\left[(1-\beta) \phi s_{F I}-\frac{n_{t} E}{k_{t} H}\right]}{\frac{2 n_{t}}{H} \int_{0}^{\frac{H}{2 n_{t}}}[1+c(z)] d z}-1 .
$$

If $n_{t}^{*}=\arg \max _{\left\{n_{t}\right\}} g_{t}^{F I}$, it then follows that $n_{t}^{*}$ satisfies the following property: ${ }^{37}$

$$
\frac{d g_{t}^{F I}}{d n_{t}^{*}} \equiv p \frac{\left[1+c\left(z_{t}^{*}\right)\right] z_{t}^{*} \beta-\int_{0}^{z_{t}^{*}}(1+c(z)] d z}{\left[\frac{1}{z_{t}^{*}} \int_{0}^{z_{t}^{*}}(1+c(z)) d z\right]^{2}}=0
$$

where $z_{t}^{*}=\frac{H}{2 n_{t}^{*}}$. It then follows that the laissez faire economy generates the optimal number of banks for any level of capital $k_{t}$ if and only if the equilibrium number of banks, $n_{t}=\zeta k_{t}$, is such that the numerator of the above expression is equal to zero. On the other hand, as long as the numerator is positive (negative) the market generates an inefficiently low (high) level of financial intermediation. In general, the sign of the above expression for different values of $k_{t}$, i.e. along the process of economic development, will depend on the shape of the cost function $c($.$) (given the other parameters). Here, we analyse the simple case in which$ $c(z)=a z$ where $a$ is a constant parameter. In this specific case the numerator

$$
\begin{array}{r}
\frac{d g_{t}^{m}}{d n_{t}}=-\frac{E}{\frac{H k_{t}}{z^{m}} \int_{0}^{z^{m}}[1+c(z)] d z}<0 . \\
37 \frac{p\left\{-\frac{E 2 n_{t} \int_{0}^{\frac{H}{2 n_{t}}}[1+c(z)] d z}{k_{t} H^{2}}-\left[(1-\beta) \phi s_{F I}-\frac{n_{t} E}{k_{t} H}\right]\left[\frac{2}{H} \int_{0}^{\frac{H}{2 n_{t}}}[1+c(z)] d z-\frac{\left(1+c\left(n_{t}\right)\right.}{n_{t}}\right]\right\}}{\left[\frac{2 n_{t}}{H} \int_{0}^{\frac{H}{2 n_{t}}}(1+c(z)) d z\right]^{2}}
\end{array}
$$


of the above expression reduces to: $(1+a z) \beta z-z-z^{2} a / 2$, where $z_{t}=\frac{H}{\zeta k_{t}} \cdot{ }^{38}$ Therefore, the economy experiences an inefficiently low (high) level of financial intermediation whenever,

$$
k_{t}<(>) \frac{a\left(\beta-\frac{1}{2}\right) H}{(1-\beta) \zeta 2} \equiv \bar{k} .
$$

First thing to be noticed is that if $\beta<\frac{1}{2}$ the economy is always characterised by excessive financial intermediation. ${ }^{39}$ Assuming $\beta>\frac{1}{2}$, we have that the economy will experience too low financial intermediation at low level of capital, i.e. $k_{t}<$ $\bar{k}$, and excessive financial intermediation at high level of capital. Therefore, in general, the amount of financial intermediation spontaneously generated by the market will be suboptimal. The intuition for that is that entrance of new banks in the market depends on economies to scale rather than economies to specialisation in the model, while growth effects depend on both. We note that this feature is due to the structure of the credit market and in particular to the structure of demand for loans, which, due to externalities, is, in equilibrium, infinitely elastic so that the effects of economies to specialisation are only on the rate of return on deposits and not on the number of intermediaries which will operate under the zero profit condition. Low levels of financial development are associated with low levels of financial development, i.e. a low number of banks. Therefore, at low levels of financial development economies to specialisation tends to be comparatively higher, i.e. $c^{\prime}\left(z_{t}\right)$ is higher, than at high level of economic development. Since the entry process in the credit market is not affected by economies to specialisation, it is intuitively clear why financial development tends to be too low at early stages of development and too high at later stages of development.

We do not regard this example, as well as the model, as a device on which rely safely for policy advises. However, the above example does give some insights on the adequacy of financial regulatory policies. Fostering concentration/competition in the credit market is going to have very different results depending on the state of economic development. Sustaining (concentration) competition might be good at early (late) stages of development while it could produce adverse growth effects at late (early) stages of development.

\footnotetext{
${ }^{38}$ Note that we assume that $a z_{t}<1$ for any $z_{t} \in \min \left[\frac{H}{2 n_{t}}, z^{m}\right]$.

${ }^{39}$ Clearly this is necessarily the case since for $\beta<\frac{1}{2}$ the RHS of the equation is negative.
} 


\section{Assessing empirical studies on growth and finance ${ }^{40}$}

Empirical literature on the relationship between financial and economic development has traditionally developed mainly along two lines: cross section/panel data studies in the style of Barro (1991), and time series analysis. Here, on the basis of the theoretical model presented, we try to interpret to which extent these two approaches help understanding direction of the causality between finance and growth.

The most known examples of cross sectional study about finance and growth come from a series of papers by King and Levine. ${ }^{41}$ Within this approach the causality issue is tackled regressing the average growth rate over long time periods on initial values (i.e. values at the starting of the period) of some measures of financial development and other explanatory variables. In particular, a measure of financial development associated with the role of banking in funding private enterprises which has been extensively use, is the ratio of loans to the private sector to GDP. Taking $t_{0}$ as the initial point in time, according to our model, that measure can be written as

$$
X_{t_{0}}=\frac{\left[s^{F I}(1-\beta) \phi-\frac{n_{t_{0}} E}{H k_{t_{0}}}\right]}{\frac{1}{z_{t_{0}}} \int_{0}^{z_{t_{0}}}[1+c(z)] d z}
$$

Similarly, considering for simplicity just the case of interbank competition, the average growth rate between $T$ and $t_{0}$ (where $T-t_{0}$ is the length of the sample period) can be written as $^{42}$

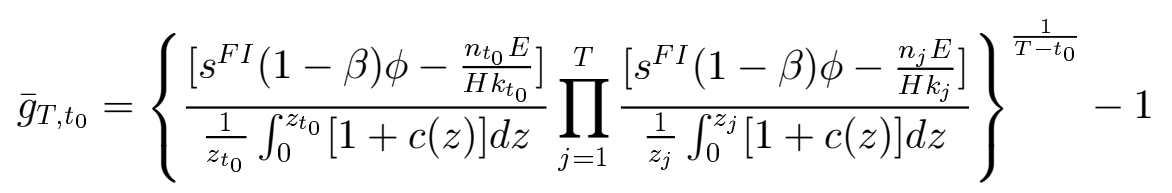

From the above expressions it is clear that a positive correlation exists between the average growth rate and the indicator of financial development, $X_{t_{0}}{ }^{43}$ However,

\footnotetext{
${ }^{40}$ The approach developed in this section is based on Tressel (1999). The conclusions about growth and finance empirics derived by the author on the basis of a theoretical model on interaction between inequalities, financial structure and growth, appear to be qualitatively similar to the ones we discuss here.

${ }^{41}$ See King and Levine (1992, 93a,b). Other examples of this strand of literature are Roubini Sala-i-Martin (1992), De Gregorio and Guidotti (1995), and Levine and Zervos (1998).

${ }^{42}$ See also Tressel (1999).

${ }^{43}$ Note that the average growth can be rewritten as
} 
as it emerges from the model, some positive correlation between $\bar{g}_{T, t_{0}}$ and $X_{t_{0}}$, is driven by common variables like the propensity to save $s^{F I}$, productivity parameters $(\psi, p, \beta)$, as well as the initial level of economic development $k_{t 0} \cdot{ }^{44}$ Given this feature, which due the fact that both $\bar{g}_{T, t_{0}}$ and $X_{t_{0}}$ are jointly endogenously determined it becomes problematic to interpret standard cross-country regressions as a solid causality test, as pointed out by Rajan-Zingales (1997), Levine, Loayza, and Beck (199?).

Long run causality is investigated also within the time series approach by means of cointegration analysis. ${ }^{45}$ Cointegration tests are performed to capture the existence of a long run relationship between the level of economic development, proxied by $y_{t}$ (or $k_{t}$ ), and indicators of financial development like, for example, the loan to the private sector/ GDP indicator, $X_{t}=\frac{\left[s(1-\beta) \phi-\frac{n_{t} E}{H t_{k}}\right]}{\frac{1}{z_{t}} \int_{0}^{z_{t}}[1+c(z)] d z}$. The causality issue here is tackled using the ECM system representation of the two cointegrated variables. ${ }^{46}$ In our view, if we take seriously the idea that financial and economic development are jointly determined, as it is in the paper we presented, a major problem arises with this approach, due to the fact that it focuses on the relationship between financial and economic development in levels. To clarify the nature of the problem using our theoretical model, it is sufficient to note that an increase in $X_{t-1}$ is always associated with an expected increase in $k_{t}$, or $y_{t}$, unless $X_{t-1}$ is less than one. ${ }^{47}$ This implies that even when financial development, i.e. an increase in $X_{t}$, affects negatively subsequent growth, we will observe a positive relationship between $X_{t-1}$ and $k_{t}$, whenever the growth rate stays positive. Now, as discussed before, during the transition period, as well as subsequently, the growth rate will be lower than under financial autarky. If so, financial devel-

$$
\bar{g}_{T, t_{0}}=\left\{\frac{\left[s^{F I}(1-\beta) \phi-\frac{n_{t_{0}} E}{H k_{t_{0}}}\right]}{\frac{1}{z_{t_{0}}} \int_{0}^{z_{t_{0}}}[1+c(z)] d z} \prod_{j=1}^{T} \frac{\left[s^{F I}(1-\beta) \phi-\frac{n_{j} E}{H k_{j}}\right]}{\frac{1}{z_{j}} \int_{0}^{z_{j}}[1+c(z)] d z}\right\}^{\frac{1}{T-t_{0}}}-1
$$

where the first term is exactly $X_{t 0}$.

${ }^{44}$ Note that: i. On average, the higher is the initial level of income, the higher would be the growth rate over the sample period; ii. Since $n_{t_{0}}$ is itself predetermined by $k_{t_{0}}$, so it is $X_{t_{0}}$.

${ }^{45}$ Examples of this literature are, Demetriades and Hussein (1996), and Arestis and Demetriades (1997).

${ }^{46}$ According to this approach, our model should give rise to a situation in which Granger's causality goes generally in both directions, which is not surpringly since both $X_{t}$ and $k_{t}$ are jointly determined by $X_{t-1}$ and $k_{t-1}$.

${ }^{47}$ This comes from the fact that $X_{t-1}$ is equal to the gross growth rate between $t-1$ and $t$. 
opment, i.e. an increase in $x_{t}$ from 0 to some positive value, has a negative on economic development. However, unless $X_{T}<1$ holds, the growth rate will be still positive which implies that next period capital, i.e. $k_{t+1}$ will be higher than $k_{t}$, so that empirically we would observe a possibly misleading positive relation exists between $X_{t}$ and $k_{t+1} \cdot{ }^{48}$

Although the task is a quite problematic and challenging one, recent research has been produced which to some extent circumvent the problems outlined above. Levine Loayza, and Beck (1998) introduce two new econometric techniques to study causality: a pure cross section estimation, and a dynamic panel one. The innovative aspect is that they introduce an instrumental variable to extract the exogenous component of financial development. This metodology, could be applied to estimate a two equations model derived from the system of dynamic relationships which characterise the theoretical model we presented. This, in order to capture both the causal link from finance to growth and that from economic to financial development.

Another recent approach put forward by Rajan and Zingales (1997) is to "[..] focus on the microeconomic details of theoretical mechanisms through which financial development affects economic growth and empirically document their working [..]". Within our model a natural way of applying this approach would be to look at the effects of financial development on the degree of competition in the credit market. ${ }^{49}$ Both directions of research seem to be more robust to criticisms than previous empirical work. The microeconometric approach seem to be more capable of producing results relevant for effective economic policies.

\section{Conclusion}

This model presents a possible justification for the existence of continuous non monotonic interaction between the process of financial deepening and economic growth. We showed a mechanism through which: i. the process of economic development induces the emergence of a credit market, and its subsequent evolution;

\footnotetext{
${ }^{48}$ As noted by Tressel (1999) this suggest thatone should look at the growth rate of $k_{t}$ or $y_{t}$ instead of the level.

${ }^{49}$ This raises the question of whether or not is an indicator like $X_{t}$ an appropriate one to measure financial development. In the case of our model this indicator does not reflect an increase in the number of operating banks unless this has an impact on the degree of competitive. In other words such an indicator would be endogenous to the existence of interbank competition, and therefore biased. This consideration leads us to the conclusions that measures like indexes of concentration in the banking sector should be more appropiate.
} 
ii. credit market development, in turns, affects the economic development process through the growth rate of the economy. The emergence of the credit market could have a negative impact on the growth rate of the economy, that could also lead to poverty traps, contrary to what generally stated by the current literature. The model also shows that, even when financial development has a positive effect on economic growth, the economy might be charactersised by a sub-optimal level of financial activity.

\section{References}

[1] Acemoglu, D. and F. Zilibotti, 1995, "Was Prometeus Unbound by Chance? Risk, Diversification and Growth", MIT WP, N.95-12;

[2] Acemoglu, D. and F. Zilibotti, 1997, "Was Prometeus Unbound by Chance? Risk, Diversification and Growth", Journal of Political Economy, 105, pp.709-755;

[3] Arestis, P. and P. Demetriades, 1997, "Financial Development and Economic Growth: Assessing the Evidence", Economic Journal, 107, pp. 783-799;

[4] Bencivenga, V.R. and B.D. Smith, 1991, "Financial Intermediation and Endogenous Growth", The Review of Economic Studies, 58, pp. 195-209;

[5] Blackburn, K. and V. Hung, 1998, "A Theory of Financial Intermediation and Growth", Economica, 65, pp. 107-124;

[6] Cameron, R. (edited by), 1967, Banking in The Early Stages of Industrialization, Oxford (UK): Oxford Un. Press;

[7] Cohen, J. S., 1967, "Italy 1861-1914", in "Banking at The Early Stages of Industrialisation, ed. by R. Cameron, Oxford (UK): Oxford Un. Press;

[8] De Gregorio, J. and P.E. Guidotti, 1995, "Financial Development and Economic Growth", World Development, 23, pp. 443-448;

[9] Demetriades, P., and Hussein, K., 1996, "Does Financial Development Cause Economic Growth? Evidence for 16 Countries", Journal of Development Economics; 
[10] Demirgüç-Kunt, A. and R. Levine, 1996a, "Stock Markets, Corporate Finance, and Economic Growth: An Overview", The World Bank Economic Review, 10, pp. 223-39;

[11] Demirgüç-Kunt, A. and R. Levine, 1996b, "Stock Market Development and Financial Intermediaries: Stylized Facts", The World Bank Economic Review, 10, pp. 291-321;

[12] Diamond, D.W., 1984, "Financial Intermediation and Delegated Monitoring", Review of Economic Studies, 51, pp. 393-414;

[13] Diamond, P., 1965, "National Debt in a Neoclassical Growth Model", American Economic Review, 55, pp. 1126-150;

[14] Frexias, X., and J. C. Rochet, 1998, Microeconomics of Banking, Cambridge (Ma): MIT Press;

[15] Gali, J. (1994), " Monopolistic Competition, Markets, and Growth", European Economic Review; 38, pp. 748-56;

[16] Goldsmith, R. W., 1969, Financial Structure and Development, New Haven (CT): Yale University Press;

[17] Goldsmith, R. W., 1987, Premodern Financial Systems: A Historical Comparative Study, Cambridge (MA): Cambridge University Press;

[18] Greenwood, J. and B. Jovanovic, 1990, "Financial Development, Growth and the Distribution of Income, Journal of Political Economy", 98, pp. 10761107 ;

[19] Gurley, J. G., and E. S. Shaw, 1955, "Financial Aspects of Economic Development", American Economic Review, 45, pp. 515-518;

[20] Gurley, J. G., and E. S. Shaw, 1960, Money in the Theory of Finance, Washington (D.C.): Brookings Institution;

[21] Gurley, J. G., and E. S. Shaw, 1967, "Financial Development and Economic Development", Economic Development and Cultural Change, 15, pp. 257-68;

[22] Hansen, G. D., and E. C. Prescott, 1998, "Malthus to Solow", NBER WP N. 6858; 
[23] Khan, A., 1999, "Financial Development and Economic Growth", MIMEO;

[24] King, R.G. and R. Levine, 1993a, "Finance and Growth, Schumpeter Might be Right", Quarterly Journal of Economics, 109, 83-109;

[25] King, R.G., and R. Levine, 1993b, "Finance, Entreprenurship, and Growth", Journal of Monetary Economics, 32, pp. 513-42;

[26] King, R.G., and R. Levine, 1992, Financial Indicators and Growth in a Cross Section of Countries, World Bank WP, N. 819;

[27] Levine, R., 1991, "Stock Markets, Growth, and Tax Policy", The Journal of Finance, 46, pp. 1445-1465;

[28] Levine R., 1992, Financial Intermediation and Economic Growth, World Bank WP, N.849;

[29] Levine, R., N. Loayza, T. Beck, 1998, "Financial Intermediation and Growth: Causality and Causes", MIMEO;

[30] Levine R., and S. Zervos, 1996, "Stock Market Development and Long-Run Growth", The World Bank Economic Review, 10, pp. 323-339;

[31] McKinnon, R.I., 1973, Money and Capital in Economic Development, Washington (DC): Brookings Institution;

[32] McKinnon, R. I., 1989, "Financial Liberalisation, and Economic Development: Reassessment of Interest Rate Policies in Asia and Latin America", Oxford Review of Economic Policy, 4, pp. 34-56;

[33] Pagano, M., 1993, "Financial Markets and Growth: An Overview", European Economic Review, 37, pp. 613-622;

[34] Rajan, R. G, and L. Zingales, 1997, "Financial Dependence and Growth", MIMEO;

[35] Roubini, N., and X. Sala-i-Martin, 1991, "Financial Development, the Trade Regime, and Economic Activity, NBER WP, N.876;

[36] Roubini, N., and X. Sala-i-Martin, 1992b, "Financial Repression and Economic Growth", Journal of Development Economics, 39, pp. 5-30; 
[37] Saint-Paul G., 1992, "Technological Choice, Financial Markets and Economic Development", European Economic Review, 36, pp. 763-781;

[38] Samolyk, K. A., 1994, "Banking Conditions and Regional Economic Performance, Evidence of a Regional Credit Channel", Journal of Monetary Economics, 34, pp. 259-278;

[39] Shaw, E.D., 1973, Financial Deepening in Economic Development, Oxford (UK): Oxford Un. Press;

[40] Sussman, O., 1993, "A Theory of Financial Development", in A. Giovannini (ed. by), Finance and Development, Issues and Experience; Cambridge (UK): Cambridge Un. Press;

[41] Sussman, O. and G. Zeira, 1996, "Banking and Development", MIMEO;

[42] Tressel, T., 1998, "Financial Structure, Inequality, and Growth", MIMEO;

[43] Usai, S., and M. Vannini, 1995, "Financial Development and Economic Growth: Evidence from a Panel of Italian Regions", CRENoS WP., N. 95/4;

[44] Van Damme, E., 1994, "Banking: A Survey of Recent Microeconomic Theory", Oxford Review of Economic Policy, 4, pp.14-33;

[45] Zilibotti, F., 1994, "Endogenous Growth and Intermediation in an Arcipelago Economy", Economic Journal, 104, pp. 462-474. 


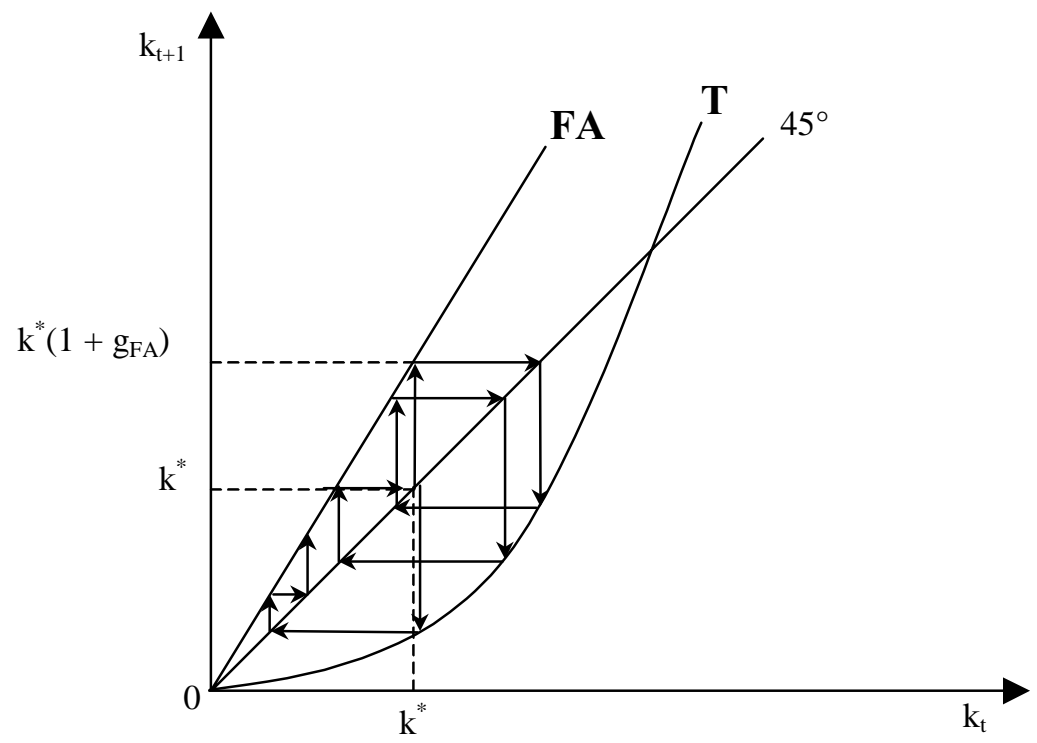

Figure 8.1: The two curves describe the accumulation equation $k_{t+1}=k_{t}(1+$ $\left.g_{i}\right)$ under two phases: financial autarky $(i=F A)$, and transition to financial intermediation, $(i=T)$. The economy shifts to financial intermediation for some $k_{T}: k_{T} \in\left[k^{*}, k^{*}\left(1+g_{F A}\right)\right)$. Transition is always associated with a negative growth rate, $g_{T}<0$, such that $k_{T * 1} \equiv k_{T}\left(1+g_{T}\right)<k^{*}$, so that transition to financial intermediation is infeasible and the economy is trapped in a low development region. 


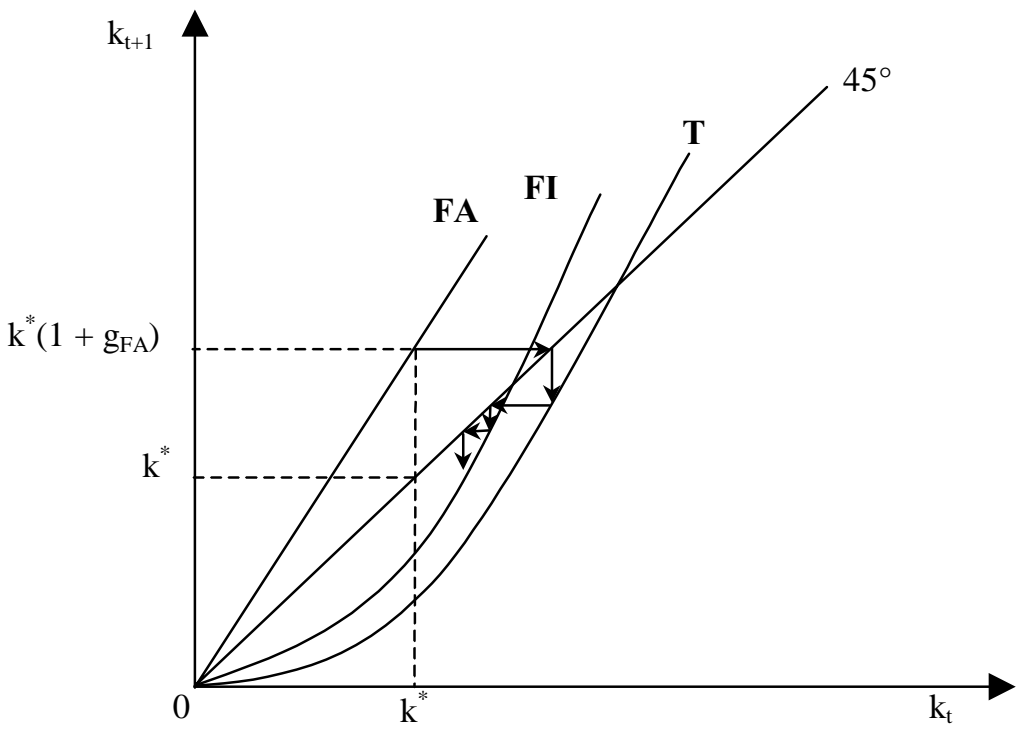

Figure 8.2: The curves $F A$ and $T$ have the same interpetation as in figure 1 . Curve $F I$ describes the accumulation equation in the post transition period. The economy shifts to financial intermediation for $k_{T} \in\left[k^{*}, k^{*}\left(1+g_{F A}\right)\right)$. For some of the possible values of $k_{T}, k_{T+1}>k_{T}$ holds, so that, at some stage, the transition to financial intermediation can be completed. However, $g_{T+1}<0$ for all possible values of $k_{T+1}$ hold, so that financial intermediation is not sustainable and the economy is trapped in a low development region. 


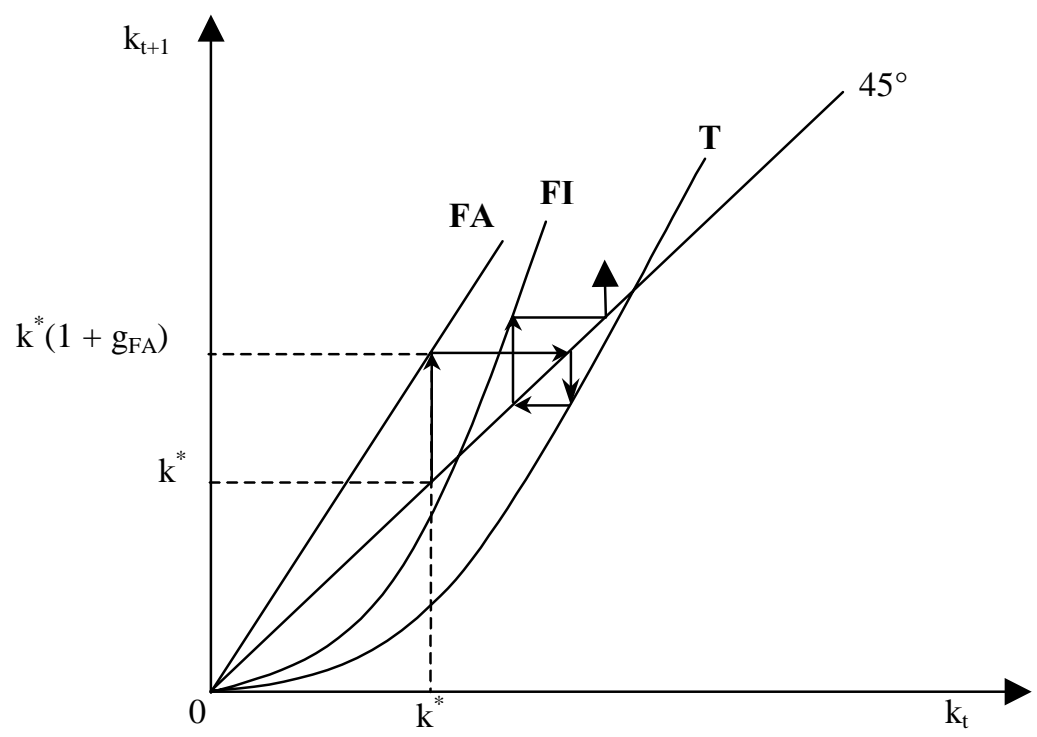

Figure 8.3: The three curves have the same interpetation as in figure 2. The economy shifts to financial intermediation for $k_{T} \in\left[k^{*}, k^{*}\left(1+g_{F A}\right)\right)$. For some of the possible values of $k_{T}, k_{T+1}>k_{T}$ and $g_{T+1}>0$ hold so that, at some stage, the transition to financial intermediation can be completed an the economy could join a path of self-sustained growth. 